ENSAYO

\title{
CRÍTICA DE CARL SCHMITT AL LIBERALISMO
}

\author{
Luis R. Oro Tapia
}

En este trabajo se recogen y comentan las críticas que el jurista y politólogo alemán Carl Schmitt (1888-1985) plantea al liberalismo. La argumentación de Schmitt no proviene de la vertiente marxista, pero tampoco es un autor que se pueda tildar sin más de conservador, de ahí su novedad y también su actualidad. El artículo analiza las críticas que Schmitt dirige a cinco aspectos emblemáticos de la doctrina liberal: el Estado de Derecho, el parlamentarismo o demoliberalismo, el pacifismo internacionalista, el individualismo y el optimismo antropológico. Esta investigación se concentra en los escritos políticos de Schmitt del período de entreguerras, que corresponde al de su mayor vitalidad intelectual y también al de sus mayores compromisos políticos.

Luis R. Oro Tapia. Licenciado en Historia, Magíster en Ciencia Política y candidato a Doctor en Filosofia. Es autor del libro ¿Qué Es la Política? (RIL Editores, Santiago, 2003) y es coautor, junto a Carlos Miranda, del libro Para Leer El Príncipe de Maquiavelo (RIL Editores, Santiago, 2001). Actualmente cumple funciones docentes en el Instituto de Historia de la Pontificia Universidad Católica de Valparaíso y en la Escuela de Periodismo de la Pontificia Universidad Católica de Chile. 


\section{Introducción}

$\mathrm{E}$ jurista y pensador político alemán Carl Schmitt (1888-1985) nunca escribió un tratado o un artículo monográfico en que abordara de manera sistemática sus críticas al liberalismo. Sus reflexiones en torno al liberalismo están confusamente desperdigadas en su copiosa obra. El tratar de espigar dichas reflexiones no es tarea fácil. En primer lugar, porque rara vez anuncia cuando va a desplegar o insinuar sus críticas. En segundo lugar, no está en modo alguno claro a qué tipo o a qué rama genealógica del liberalismo está impugnando, pero lo que sí es evidente es que en sus escritos están ausentes los pensadores liberales de la segunda mitad del siglo veinte. En tercer lugar, Schmitt no es un pensador sistemático; tiene, especialmente en sus ensayos políticos, cierto matiz de polemista ocasional y ciertos visos de sofista, en cuanto en algunos de sus escritos utiliza un argumento para atacar y en otros utiliza el mismo argumento para defender una causa que a él le interesa.

Entonces, ¿cómo identificar cuál es la crítica de Carl Schmitt al liberalismo? En mi opinión, tal problema se puede solucionar en parte formulando otra pregunta: ¿cuáles son las características comunes, no obstante su diversidad, de las diferentes corrientes del liberalismo? Creo que la numerosa y heterogénea familia liberal coincide en los siguientes aspectos: en la necesidad de instituir un Estado de Derecho; en la defensa de la libertad individual; en la restricción del uso de la fuerza como instrumento de la política exterior de los Estados, y en la concepción optimista de la naturaleza humana que subyace, con diferentes énfasis, en las diversas corrientes del liberalismo. A estos cuatro aspectos señalados hay que agregar - como quinto punto- el parlamentarismo, que fue el régimen predominante en Europa central y occidental durante la segunda mitad del siglo XIX y principios del $\mathrm{XX}$, que es el período que corresponde a la formación intelectual de Schmitt y que es precisamente frente al cual él reacciona de manera crítica.

En este trabajo abordaré la manera en que fueron tratados dichos aspectos en algunos escritos del referido autor, correspondientes al período de entreguerras. Como método de trabajo trataré de fundamentar cada una de las afirmaciones que realice respecto de sus planteamientos en sus propios escritos. Por eso, constantemente utilizaré el pie de página para dar las referencias precisas en las que mi análisis se sustenta.

\section{Crítica al Estado de Derecho}

Para comprender la crítica que realiza Carl Schmitt a esta idea emblemática del liberalismo, previamente hay que explicar el concepto de deci- 
sión. Este concepto, a su vez, remite a tres ideas que le anteceden: las de normalidad, excepción y soberanía. Explicaré cada una de ellas por separado, después esbozaré la noción de Estado de Derecho y, finalmente, las críticas que Schmitt le formula.

¿Qué es la normalidad? Es la plena vigencia del Estado de Derecho y en general de cualquier orden jurídico. Ello supone, desde el punto de vista legal, el funcionamiento normal de las instituciones, $\mathrm{y}$, desde el punto de vista empírico, la existencia de paz interna y externa. La normalidad implica la observancia de la legalidad y una sociedad en la que impera el orden, en cuanto ella funciona de acuerdo a lo que las leyes prescriben ${ }^{1}$. En efecto, la vigencia de las normas supone una situación de normalidad ${ }^{2}$. Entonces, la normalidad implica la existencia de un orden concreto que funciona regularmente, en cuanto se ajusta a la realidad prevista por las normas.

¿Qué es lo excepcional? El caso excepcional es aquella eventualidad o contingencia que no está descrita ni prevista por el orden jurídico vigente y que puede definirse como un caso de necesidad extrema, de peligro para la existencia del Estado o algo semejante ${ }^{3}$. Puesto que el caso excepcional es un evento no previsto en el ordenamiento constitucional, no se le debe confundir con el estado de sitio ni otra figura jurídica similar ${ }^{4}$. Se trata de situaciones o casos no tipificados por el orden jurídico vigente. No toda facultad extraordinaria ni cualquier medida policíaca o decreto de emergencia equivalen automáticamente a un estado de excepción, puesto que ellos generalmente están previstos en los ordenamientos constitucionales 5 . Entonces, el caso excepcional se presenta cuando no existen normas para resolver un conflicto o bien cuando éstas existen, pero son conculcadas por los contendientes.

Para que una situación sea calificada de excepcional, no basta con que se presente un caso no previsto por el ordenamiento institucional. Además es necesario que se dé en un contexto de una lucha por el poder de tal magnitud que sea capaz de agrupar a los oponentes en amigos y enemigos.

${ }^{1}$ Cf. Schmitt, Carl: Teología Política, 1998, p. 25.

${ }^{2}$ Cf. Schmitt, Carl: Sobre los Tres Modos de Pensar la Ciencia Jurídica, 1996, p. 24.

${ }^{3}$ Cf. Schmitt, Carl: Teología Política, 1998, pp. 16-17.

${ }^{4}$ Es pertinente realizar la siguiente aclaración para evitar malos entendidos. En el lenguaje del derecho constitucional chileno se usa la palabra excepcional en la expresión compuesta "estado de excepción". En el caso chileno el estado de excepción tiene cuatro variantes: estado de emergencia, estado de conmoción, estado de sitio y estado de asamblea. Todos ellos están normados, en cuanto están previstos por el ordenamiento constitucional chileno. En cambio, en el lenguaje de Carl Schmitt la palabra excepcional y más precisamente la expresión "caso excepcional” alude a una situación absolutamente anormal o extralegal.

${ }^{5}$ Cf. Schmitt, Carl: Teología Política, 1998, p. 23. 
En un contexto de tal índole, la solución que se proponga al caso no contemplado por la legalidad difícilmente puede ser aceptada sin más, o sea pasivamente, por los afectados. El caso excepcional se da en un contexto de juego de suma cero, en cuanto la intensidad del conflicto impide a los antagonistas llegar a una solución negociada o de consenso.

En tales casos, que generalmente son de conflicto extremo, surge la siguiente interrogante: ¿quién dispone de las facultades no regladas constitucionalmente, es decir, quién es competente cuando el orden jurídico no resuelve el problema de la competencia? En casos así, la Constitución a lo más puede indicar quien tiene permitido actuar, pero no quien debe tomar la decisión. Sólo en estas circunstancias cobra actualidad la pregunta acerca del sujeto de la soberanía y la interrogante por el concepto mismo de soberanía 6 . La respuesta de Schmitt es perentoria: soberano es aquel que decide sobre el estado de excepción ${ }^{7}$. Por cierto, el soberano decide si existe el caso de excepción extrema y también lo que debe hacerse para remediarlo ${ }^{8}$. Entonces, soberano es aquel que decide inapelablemente en caso de conflicto extremo y su decisión tiene por finalidad inmediata terminar con el desorden, frente a lo cual tiene dos opciones: restaurar el orden que ha sido quebrantado o bien crear uno completamente nuevo.

Desde el punto vista jurídico político el caso excepcional es aquel que escapa a toda determinación normativa, puesto que no se puede resolver por la vía legal. Pero, por otra parte, pone al descubierto en toda su pureza el momento específicamente político, en cuanto queda en evidencia la manera como se instaura el orden jurídico a través de una decisión, de un golpe de timón que se sustenta solamente en la voluntad de poder desnuda. Así, la situación excepcional tiene un carácter fundacional, porque instituye un orden y configura las circunstancias dentro de las cuales van a tener validez los preceptos jurídicos de reciente creación.

¿Qué se entiende por decisión? La decisión soberana es extrajurídica, puesto que se libera de todas las trabas normativas y se torna absoluta, en cuanto no obedece a ningún tipo de patrón legal preestablecido. Ante "un caso excepcional, el Estado suspende el derecho en virtud del derecho a la propia conservación”9. Por el contrario, en los casos normales cabe reducir al mínimo el elemento autónomo de la decisión, es decir, la posibilidad de tomar una resolución al margen del orden jurídico.

${ }^{6}$ Cf. Schmitt, Carl: Teología Política, 1998, p. 17.
7 Cf. ibídem, p. 15. También véase Schmitt, Carl: Sobre el Parlamentarismo, 1990, p. 55.

${ }^{8}$ Cf. Schmitt, Carl: Teología Política, Schmitt, Carl: 1998, pp. 16 y 17.

${ }^{9}$ Ibídem, p. 24. 
Así, la autoridad demuestra que para crear derecho no necesita tener derecho ${ }^{10}$; dicho en palabras de Hobbes: auctoritas, non veritas facit legem. La decisión soberana "no se explica jurídicamente ni desde una norma, ni desde un orden concreto, ni encuadra en un orden concreto. Sólo la decisión funda tanto la norma como el orden. La decisión soberana es el principio absoluto y el principio no es otra cosa que la decisión soberana”11. En efecto, soberano es quien crea el orden político y legal a partir de una situación ilegal.

El Estado de Derecho tiene su origen en una decisión, pero una vez que la decisión ha producido la norma, ésta también impone sus exigencias al legislador, por tanto, el legislador queda sometido a la legalidad que él mismo ha instituido ${ }^{12}$. El creador — vale decir, el legislador — queda sometido a su propia creación, a las reglas que él mismo ha dictado. El poder constituyente queda así enjaulado en su propia producción normativa. En efecto, la norma una vez dictada, debe valer también frente a la voluntad del que la ha impuesto; si no, no se podría conseguir la ordenación y estabilización de las relaciones de poder en el espacio que el Estado controla ${ }^{13}$. Así, el objetivo del legislador ${ }^{14}$ que instaura el Estado de Derecho es que su decisión siga valiendo de modo fijo e inquebrantable como norma, por tanto, el legislador estatal también se somete a la ley por él puesta y a su interpretación. Éste es el único sistema de gobierno considerado Estado de Derecho, aunque en realidad sea un estado legal lo que se defiende, en cuanto se coloca el interés de la seguridad jurídica por sobre la justicia ${ }^{15}$.

Cuando Carl Schmitt emplea la expresión Estado de Derecho lo hace teniendo presente el significado que otorga a tal expresión Anschütz, quien lo define como "un Estado que se halla totalmente bajo el signo del derecho, cuya voluntad suprema no se llama Rex sino Lex; una comunidad en la que las relaciones entre los individuos, no solamente entre sí, sino sobre todo con el poder estatal, se determina a través de los preceptos legales; en el que entre gobernantes y gobernados todo sucede según el derecho y no según el tel est notre plaisir de los gobernantes. El orden jurídico debe mantenerse inviolable y la ley debe aparecer como un poder que está orde-

10 Cf. Schmitt, Carl: Teología Política, 1998, p. 25.

11 Schmitt, Carl: Sobre los Tres Modos de Pensar la Ciencia Jurídica, 1996, pp. 30 y 31.

12 Ibídem, p. 39.

13 Ibídem, p. 42.

${ }^{14}$ Aquí nos referimos al legislador del poder constituyente; no al legislador ordinario que evacua leyes de acuerdo a los procedimientos estipulados por la Constitución. pp. 38-39.

15 Cf. Schmitt, Carl: Sobre los Tres Modos de Pensar la Ciencia Jurídica, 1996, 
nado por encima de la voluntad tanto de los gobernados como de las personas que gobiernan"16.

Carl Schmitt emplea de manera intercambiable las expresiones Estado de Derecho ${ }^{17}$ y Estado Legislativo ${ }^{18}$. ¿Qué quiere significar con la expresión Estado Legislativo? Para Schmitt es aquel que está regido por normas impersonales, generales y predeterminadas y en él la elaboración de la ley y la aplicación de ella corresponden a diferentes órganos del Estado. Ésta es la definición — concluye Schmitt- de lo que hasta ahora se ha llamado Estado de Derecho ${ }^{19}$. En definitiva, en el Estado de Derecho las competencias del poder estatal están fijadas por la ley positiva y sus atribuciones están claramente delimitadas y predeterminadas, por tanto, sus actos son impersonales, objetivos y previsibles ${ }^{20}$.

Pero puesto que una ley no puede aplicarse o ejecutarse a sí misma y no puede ni interpretarse, ni definirse, ni sancionarse; tampoco puede por sí sola nombrar o designar a las personas concretas que deben aplicarla e interpretarla ${ }^{21}$. En efecto, "ninguna norma, ni superior ni inferior, se interpreta y aplica, se protege o salvaguarda por sí misma; y tampoco hay — $\mathrm{si}$ no se quiere entrar en metáforas o alegorías - ninguna jerarquía de normas, sino tan sólo una jerarquía de hombres e instancias en concreto"22. Así, tras la aparente despersonalización de la ley y de la frialdad del imperio del derecho sigue operando desde las penumbras la voluntad humana y sus respetivas valoraciones e intereses.

Desde el punto de vista meramente formal, y sin querer trascender a éste, el Estado de Derecho no sería otra cosa que "un aparato de aplicación de normas, para el uso del cual se precisa, más que una formación jurídica, un conveniente aprendizaje técnico de un buen guardagujas”23. Por su-

${ }^{16}$ Ibídem, pp. 13-14 (nota 2). También véase Schmitt, Carl: Sobre el Parlamentarismo, 1990, p. 55.

${ }^{17}$ El Estado de Derecho es "un sistema de legalidad cuyos instrumentos de trabajos son leyes escritas, pero sobre todo códigos, y se funda en una Constitución hecha por hombres. El Estado de Derecho burgués no es más que un Estado de leyes”. Schmitt, Carl: El Leviatán en la Teoría del Estado de Thomas Hobbes, 1990, p. 66.

${ }^{18}$ Para Schmitt, en el Estado Legislativo existe una separación de funciones, en cuanto una instancia elabora las normas y otra las aplica, y en él no mandan los hombres, ni siquiera los legisladores, sino que las leyes. Cf. Schmitt, Carl: Legalidad y Legitimidad, 1994, p. 74.

${ }^{19}$ Cf. Schmitt, Carl: Sobre los Tres Modos de Pensar la Ciencia Jurídica, 1996, p. 37 (nota 17).

${ }^{20}$ Cf. Schmitt, Carl: Legalidad y Legitimidad, 1994, p. 41.

${ }^{21}$ Cf. Schmitt, Carl: Sobre los Tres Modos de Pensar la Ciencia Jurídica, 1996, p. 16 .

${ }^{22}$ Schmitt, Carl: Legalidad y Legitimidad, 1994, p. 74.

${ }^{23}$ Schmitt, Carl: Sobre los Tres Modos de Pensar la Ciencia Jurídica, 1996, p. 38. Una reflexión similar también se encuentra en el libro de Schmitt El Leviatán en la Teoría del Estado de Thomas Hobbes, 1990, p. 69. 
puesto que tal habilidad reviste caracteres de virtud cuando impera la normalidad, esto es, la regularidad del orden administrativo y judicial. Pero ¿qué sucede en tiempos de crisis?

El Estado de Derecho parte, generalmente, del supuesto de que impera la paz social y la concordia política interna y son, precisamente, tales condiciones óptimas las que le permiten aplicar sus normas sin riesgo de desobediencia ni de impugnación ${ }^{24}$. Tales supuestos no son utópicos, más bien son insólitos. En efecto, la experiencia histórica demuestra que en los momentos de crisis, cuando la pugna entre los antagonistas alcanza el umbral de la hostilidad, los sujetos involucrados en un diferendo impugnan la legalidad vigente, la legitimidad de los veredictos y las intenciones de los jueces.

La doctrina del Estado de Derecho niega el caso excepcional, porque concibe al orden jurídico como un sistema de reglas autosuficiente que puede resolver todos los problemas a partir de las normas. A este supuesto se le puede objetar que, por muy previsor que sea el legislador, siempre existe la posibilidad de que se presenten situaciones que escapen al ordenamiento normativo.

Desde el punto de vista formal, en síntesis, el Estado de Derecho "se caracteriza por poner en un lado la norma y en otro lado, y separado de ella, la ejecución de la norma. De ahí nace su peculiar sistema de legalidad, del que puede decirse con cierta justificación que en él no mandan hombres ni autoridades, ni acaso tampoco los cuerpos legislativos, sino que tan sólo rigen normas desligadas de ellos" ${ }^{\text {25 }}$. Pero, como ya se explicó, tras él se ocultan las relaciones de poder; por consiguiente, una de las finalidades políticas del Estado de Derecho es intentar disimular o encubrir las auténticas relaciones de poder, bajo la apariencia de la impersonalidad, objetividad y neutralidad de las normas.

\section{Crítica al parlamentarismo o demoliberalismo}

El liberalismo propicia la publicidad y transparencia de la actividad política. El demoliberalismo quiso terminar con la política de gabinete y con los secretos de Estado, pero incurrió en dos prácticas análogas: la política de camarillas y el hermetismo del trabajo en comisiones. La burguesía, en su lucha contra la monarquía absoluta, opuso a la doctrina de la razón de

${ }^{24}$ Cf. Schmitt, Carl: Legalidad y Legitimidad, 1994, p. 89.

${ }^{25}$ Ibídem, p. 74. 
estado y de los arcana imperii ${ }^{26}$ el ideal de la transparencia y de la publicidad de los actos de gobierno. Una de las finalidades originarias del parlamento era transparentar, mediante la antorcha de la razón pública y de la libre discusión, la manera como la autoridad gubernamental toma sus resoluciones. Tal motivación tenía por meta superar la política secreta de los príncipes y de los consejos de gabinete. Este nuevo ideal concebía la política de gabinete, ejecutada por unas cuantas personas a puertas cerradas, como algo en sí mismo malvado y, por tanto, la publicidad de la vida política, por el mero hecho de ser tal, como algo bueno y saludable ${ }^{27}$.

Sin embargo, la aspiración de transparencia y publicidad que pregonaba el liberalismo pronto devino en prácticas que negaban dicha expectativa. En efecto, en la Era Liberal las cada vez más pequeñas comisiones de partidos, o de coaliciones de partidos, deciden a puertas cerradas sobre aquello que afecta diariamente la vida de los ciudadanos. Más aún, los parlamentarios no deciden de manera autónoma, sino que deciden como representantes de los intereses del gran capital. Y estos últimos, a su vez, toman sus decisiones en un comité más limitado que afecta, quizás de manera mucho más significativa, la vida cotidiana de millones de personas. De hecho, las decisiones políticas y económicas, de las cuales depende el destino de las personas, no son (si es que alguna vez lo han sido) ni el fiel reflejo de la sensibilidad de la ciudadanía ni del debate público que en torno a ellas se pueda suscitar ${ }^{28}$. Si la política de camarillas y el hermetismo del trabajo en comisiones se han convertido en la negación del discurso normativo liberal, que propiciaba la publicidad y la discusión, es natural que "la fe en la discusión pública tenía que experimentar una terrible desilusión”29. En efecto, el funcionamiento del sistema demoliberal de gobierno ha resultado ser un fiasco, porque la evolución de la moderna democracia de masas ha convertido el eslogan de la discusión pública en una mera formalidad vacía ${ }^{30}$. Por cierto, la verdadera actividad política no se desarrolla en los debates públicos del pleno, puesto que las decisiones realmente importantes han sido tomadas previamente en las comisiones o "en reuniones secretas de los jefes de los grupos parlamentarios e, incluso, en comisiones no parlamentarias. Así, se origina la derivación y supresión de todas las responsabi-

${ }^{26}$ Para dimensionar el alcance de ambos conceptos véase la monografía de Carl Schmitt titulada La Dictadura, desde los Comienzos del Pensamiento Moderno de la Soberanía hasta la Lucha Proletaria, 1999, especialmente de la página 44 a 53.

${ }^{27}$ Cf. Schmitt, Carl: Sobre el Parlamentarismo, 1990, p. 49.

${ }^{28}$ Cf. ibídem, p. 64.

${ }^{29}$ Cf. ibídem, p. 65.

${ }^{30}$ Cf. ibídem, p. 9. 
lidades, con lo que el sistema parlamentario resulta ser, al fin, sólo una mala fachada del dominio de los partidos y de los intereses económicos”31.

Para Schmitt el Estado demoliberal es incapaz de actuar como unidad de decisión y de acción frente a situaciones límites. El liberalismo frente a un dilema que impele a tomar una determinación rápida queda atónito y elude tomar pronta y resueltamente un curso de acción a seguir. Así, por ejemplo, frente a la pregunta perentoria: “¿a quién queréis, a Barrabás o a Jesús?”32, la urgencia de la respuesta queda aplazada con el nombramiento de una comisión parlamentaria investigadora que finalmente elude dar una respuesta concluyente. Para Schmitt, la esencia del liberalismo radica en la negociación y la indecisión permanente, puesto que tiene la expectativa de que en el debate parlamentario el problema se diluya, suspendiéndose así indefinidamente la resolución mediante la discusión eterna ${ }^{33}$.

En el parlamentarismo, el pueblo como unidad orgánica, vale decir como totalidad, no está representado en el parlamento; por consiguiente, el régimen parlamentario no es democrático. Entonces, ¿̇a quiénes representan los parlamentarios? La respuesta teórica es a la nación, a la comunidad, a un todo orgánico. Sin embargo, en la práctica no es así, porque los parlamentarios representan a partidos políticos, tras los cuales están determinados intereses, y ellos están más preocupados de aumentar o de preservar sus cuotas de poder, que les permiten proteger sus respectivos intereses, que de velar por el bienestar del todo orgánico. Los partidos se relacionan entre sí "como poderosos grupos de poder social y económico, calculando los mutuos intereses y sus posibilidades de alcanzar el poder y llevando a cabo desde esta base fáctica compromisos y coaliciones"34.

Schmitt afirma que en el parlamento no hay discusión, pero sí negociación y ajuste de intereses entre los partidos que tienen representación parlamentaria. Por tal motivo, Schmitt sostiene que afirmar que los parlamentarios alientan una genuina discusión pública sería faltar a la verdad. La brecha entre el ideal y la realidad es ostensible; en efecto, las relaciones entre los parlamentarios distan mucho del modelo de discusión pública que proponía Bentham. Este teórico del liberalismo sostenía que en el parlamento se encuentran las ideas y el contacto entre ellas hace saltar las chispas de la evidencia ${ }^{35}$. Pero, en la práctica, no hay discusión razonada ni debate público, sino negociaciones de antesala en la que los partidos tienen por

\footnotetext{
${ }^{31}$ Schmitt, Carl: Sobre el Parlamentarismo, 1990, p. 25.

32 Schmitt, Carl: Teología Política, 1998, p. 85.

${ }^{33}$ Cf. ibídem, p. 86.

${ }^{34}$ Schmitt, Carl: Sobre el Parlamentarismo, 1990, p. 9.

${ }^{35}$ Cf. ibídem, p. 10.
} 
principal preocupación la defensa de sus intereses sectoriales y el cálculo estratégico de sus oportunidades para incrementar o conservar sus cuotas de poder.

Entonces, el debate público resulta ser una quimera. En efecto, en vez de prosperar una discusión en la que prevalece la argumentación racional, irrumpe la propaganda que tiene por objetivo seducir la emotividad del electorado. Así, la discusión pública primero es sustituida por la excitación de la sensibilidad e inmediatamente después por la movilización de las pasiones, lo cual se logra a través de afiches, carteles, consignas y otros medios que tienen por finalidad sugestionar a las masas.

¿Por qué el parlamentarismo está en crisis? Dicho en nuestro lenguaje: ¿Por qué la democracia liberal está en crisis? ¿Qué explica el desafecto que existe por ella? La democracia liberal como institución ha perdido sus raíces ciudadanas, manteniéndose sólo como un dispositivo formal vacío, como un organismo carente de un pathos, que funciona más por inercia y por falta de una mejor opción que por convicción ${ }^{36}$. El languidecimiento del pathos del parlamentarismo ha debilitado la identidad existente entre representantes y representados; por consiguiente, el sistema demoliberal deviene, paradojalmente, en un régimen no democrático; concebida la democracia como la entiende Schmitt. ¿Qué es la democracia para Schmitt? Es, simplemente, la identidad que existe entre gobernantes y gobernados; entre la nación y el Estado; entre los seguidores y el líder; entre electores y elegi$\operatorname{dos}^{37}$, etc.

En las sociedades que poseen regímenes políticos demoliberales el afán de dar satisfacción a los intereses individuales y sectoriales en desmedro de la comunidad ha erosionado la moral pública. Tanto es así que en algunos Estados demoliberales "todos los asuntos públicos se han convertido en objeto de botines y compromisos entre los partidos y sus seguidores y la política, lejos de ser el cometido de una elite [de servidores públicos], ha llegado a ser el negocio, por lo general despreciado, de una, por lo general despreciada, clase"38, concluye Schmitt.

\section{Crítica al internacionalismo pacifista}

El liberalismo aspira a construir una legalidad internacional similar a la vigente al interior de los Estados liberales. Tal legalidad tendría primordialmente dos objetivos: bloquear el uso de la violencia a través de un

36 Cf. Schmitt, Carl: Sobre el Parlamentarismo, 1990, p. 27.

${ }^{37}$ Cf. ibídem, pp. 18, 19, 33 y 34.

38 Ibídem, p. 7. 
dispositivo de normas y funcionar como instancia de resolución de conflictos internacionales. La meta es construir una réplica del Estado de Derecho, pero a nivel internacional. Cuando se estuvo más cerca de plasmar este ideal en la realidad fue en los años inmediatamente posteriores al Tratado de Versalles. De hecho, a principios de la década de 1920 surgió "una actividad jurídica internacional que tenía cierta similitud aparente con la actividad jurídica interior de un Estado. Esto llevaba a la idea falsa de que todo lo que había surgido dentro del Estado en jurisprudencia, métodos procesales y ciencia jurídica, podía aplicarse desde la vida jurídica interior del Estado a la actividad jurídica internacional de los Estados"39. Por cierto, se intentó reproducir la racionalidad jurídica que imperaba al interior del Estado a las relaciones jurídicas entre los Estados. Pero al igual que en el plano interno cabe preguntarse quién dicta las reglas y en beneficio de quién. En efecto, en lo que respecta a la construcción de la legalidad internacional también es aplicable la sentencia hobbeseana "auctoritas, non veritas facit legem", que tan reiteradamente cita Schmitt. Por consiguiente, la legalidad internacional también sería expresión de las relaciones de poder existentes entre los Estados y dicha legalidad también respondería a determinados intereses y a ella también serían imputables las inconsistencias que posee el Estado de Derecho en el plano interno.

Para un Estado débil que esté imbuido de la ideología liberal "sería una torpeza creer que un pueblo no tiene más que amigos, y un cálculo escandaloso suponer que la falta de resistencia va a conmover al enemigo" ${ }^{40}$. En el supuesto que una comunidad políticamente organizada decida renunciar al ius belli y a distinguir, por consiguiente, entre amigos y enemigos, ello no implica en modo alguno que se evapore la política y que, acto seguido, se extingan todas las relaciones de poder en el planeta. Nada de eso ocurriría. Por cierto, en la eventualidad de que un pueblo haya perdido la fuerza o la voluntad para sostenerse en la esfera de lo político, no implica en modo alguno que vaya a desaparecer la política del mundo; "lo único que desaparecerá en ese caso será un pueblo débil”41, concluye Schmitt.

La política, hipotéticamente, llegará a su fin cuando no exista ninguna posibilidad de que se constituya la relación amigo-enemigo; en tal caso la probabilidad de que estalle un conflicto violento sería nula. ¿Será ello factible? Aunque Schmitt no lo hace, sería conveniente preguntarse, junto con Maquiavelo ${ }^{42}$, si la naturaleza humana permite tanta perfección. Para

\footnotetext{
39 Schmitt, Carl: Escritos de Política Mundial, 1995, p. 44.

${ }^{40}$ Schmitt, Carl: El Concepto de lo Político, p. 82.

41 Ibídem.

${ }^{42}$ Cf. Maquiavelo, Nicolás: El Príncipe, Capítulo XV.
} 
Schmitt, quien tiene una visión hobbeseana de la naturaleza humana, una sociedad universal pacífica, similar al Estado Homogéneo Universal que concibe Fukuyama ${ }^{43}$, es algo imposible. No solamente porque no existirían pueblos que constituyan unidades políticas (en el sentido schmittiano de la expresión), sino porque, además, tampoco habría antagonismos ni grupos hostiles capaces de configurar la relación amigo-enemigo ${ }^{44}$. En última instancia, la política es ineludible, puesto que por naturaleza el hombre es un ser conflictual y es precisamente el antagonismo el que suscita la dinámica de la relación amigo-enemigo ${ }^{45}$.

Pero si se lograra instaurar, como aspira el liberalismo, algo similar al Estado de Derecho en el plano de las relaciones internacionales, ello no implicará en modo alguno la completa eliminación del uso de la fuerza. La coacción física seguirá usándose, pero cambiará la denominación del sujeto sobre el cual se aplicará la fuerza y también la forma como se justificará su uso. El sujeto ya no será un enemigo, sino que será un criminal, un delincuente, un infractor del orden y de la legalidad internacional. En efecto, él ya no tendrá el status de enemigo político, sino que será un delincuente y sobre él se dejará recaer todo el peso de la ley, el que en última instancia se hace efectivo a través de los dispositivos de coacción física que asisten a las normas jurídicas. Según Schmitt, para la puesta en práctica de tal orden, el liberalismo ha creado todo un arsenal semántico ${ }^{46}$, un nuevo vocabulario,

${ }^{43}$ Cf. Fukuyama, Francis: ¿El Fin de la Historia?, 1991.

${ }^{44}$ Schmitt, Carl: El Concepto de lo Político, 1991, p. 84.

${ }^{45}$ Cf. ibídem, pp. 87 y 88.

${ }^{46}$ El imperialismo crea sus propios conceptos e impone su lenguaje. Uno de los fenómenos más sutiles y significativos de la dominación política es que el poderoso define por sí mismo, y en función de sus propios intereses, la terminología y la gramática política. Un requisito básico de todo imperialismo para que sea históricamente significativo no es solamente su poderío militar, sino que también su capacidad para determinar, de acuerdo a sus intereses, el significado de los conceptos políticos y jurídicos fundamentales que rigen el orden internacional. Es expresión del poder político genuino de un pueblo con vocación imperialista el tener la capacidad para influenciar, e incluso determinar, la manera de pensar de otros pueblos, a través del vocabulario, la terminología, los conceptos. Es crucial que el poderoso monopolice la definición e interpretación de los conceptos políticos clave, como por ejemplo: paz, desarme, intervención, agresión, seguridad, orden, etcétera y que, además, tenga la capacidad de decisión para aplicarlos en situaciones concretas. El transigir a la semántica jurídica y política del imperialismo puede ser sumamente riesgoso para un Estado débil, quizás más peligroso que el sometimiento militar y la explotación económica. Por el contrario, un pueblo permanecerá libre, por lo menos en la esfera del espíritu, si se resiste a asumir el lenguaje político del imperio y especialmente si no se somete al derecho internacional que trata de imponer el poderoso. Cf. "El Imperialismo Moderno en el Derecho Internacional Público”. Este artículo fue publicado en 1932 y está incluido en la compilación escritos políticos de Carl Schmitt realizada por Héctor Orestes Aguilar, publicada con el título Carl Schmitt, Teólogo de la Política, 2001, p. 95 a 113. 
esencialmente pacifista, que "ya no conoce la guerra sino únicamente ejecuciones, sanciones, expediciones de castigo, pacificaciones, protección de pactos, medidas para garantizar la paz [y] al adversario ya no se llama enemigo, pero en su condición de estorbo y ruptura de la paz se lo declara hors-la-loi y hors l'humanité" 47 .

\section{Crítica al individualismo}

Para el liberalismo la enemistad siempre es un asunto privado, cada sujeto decide individualmente y de manera autónoma quién es su enemigo. A ningún sujeto se le puede imponer un enemigo (privado o público) si él, individual y subjetivamente, no lo acepta como tal. De acuerdo a la doctrina liberal, según Schmitt, el Estado no puede imponerle enemigos al individuo ni exigirle que los combata poniendo en riesgo su propia vida. Pero éste puede morir de manera voluntaria por aquello que a él, individualmente, le plazca. Esto, como todo lo esencial en una sociedad liberal individualista, es desde luego cuestión privada, por tanto, es resolución personal, libre y autónoma, no sometida a ninguna injerencia externa y menos aún a la del Estado. La determinación sobre cómo debe morir no concierne a nadie más que a él como individuo y al respecto toma su personal y libre resolución ${ }^{48}$.

Para el liberalismo no existen enemigos colectivos. Por tal motivo, un Estado que sea liberal a cabalidad no puede disponer abiertamente de la vida de sus ciudadanos. No obstante, históricamente, el Estado es el que decide quién es el enemigo y él es quien determina los medios para combatirlo. Más aún, el Estado en caso extremo puede exigir a sus ciudadanos que den la vida por la comunidad política si fuese necesario. De hecho, una unidad política puede pedir a sus miembros, en caso extremo, que sacrifiquen sus respectivas vidas por el bien de la comunidad. Para el liberalismo "semejante pretensión no es ni asequible ni susceptible de fundamentación”49. Aceptar tal requerimiento sería un contrasentido, puesto que un individualismo que pusiese en manos ajenas la capacidad de disponer de la propia vida, "no pasaría de ser una palabra vacía, como lo sería igualmente una libertad liberal cuyos contenidos y alcances fuesen determinados por otro distinto del propio ser libre" ${ }^{\text {. }}$. De acuerdo a la concepción liberal, para el individuo como tal no existe enemigo al que haya que combatir a vida o muerte si él no lo quiere personalmente; obligarle a combatir contra su vo-

\footnotetext{
${ }^{47}$ Schmitt, Carl: El Concepto de lo Político, 1991, p. 106.

${ }^{48}$ Cf. ibídem, p. 78.

${ }^{49}$ Ibídem, p. 99.

${ }^{50}$ Ibídem.
} 
luntad sería, desde el punto de vista del individuo, violentar su libertad y su privacidad y disponer de su cuerpo a costa de su conciencia.

Para el liberalismo "no existe programa, ideal, norma ni racionalidad que otorguen el derecho a disponer de la vida física de otras personas [y] no existe objetivo tan racional, ni norma tan elevada, ni programa tan ejemplar, ni legalidad, ni legitimidad alguna que puedan justificar el que determinados hombres se maten entre sí por ellos"51. Entonces, la destrucción física de la vida humana no tiene justificación posible, a no ser que se produzca una amenaza de tal envergadura sobre la propia vida, en el plano privado, que para conservar su existencia el individuo tenga que recurrir necesariamente a la violencia, por tanto, solamente es excusable dar muerte a otra persona en defensa propia.

Pero como el Estado aún sigue disponiendo del ius belli, puede disponer de la existencia física de sus ciudadanos, ordenándoles a éstos, en ciertas circunstancias, dar muerte a determinadas personas en nombre de la seguridad del Estado ${ }^{52}$. Por cierto, el Estado soberano posee el ius vitae ac necis, esto es, el derecho sobre la vida y la muerte de sus miembros. El Estado moderno, desde sus inicios, paulatinamente fue expropiando esta prerrogativa a los particulares hasta monopolizarla y en la actualidad es factible que el Estado la enajene a otra entidad como, por ejemplo, un tribunal penal internacional. El debilitamiento de la soberanía estatal en la última década, no implica en modo alguno la extinción de la soberanía. La soberanía puede cambiar de titular, de sede, de morada; así por ejemplo, en la actualidad hay algunos indicios para conjeturar que la soberanía está en tránsito, en cuanto está comenzando a desplazarse, al parecer, desde los Estados a los organismos internacionales. Pero tal migración en modo alguno significa la extinción de ella y menos aún de las relaciones de poder.

En definitiva, el liberalismo se opone a que el Estado disponga abiertamente de la vida de sus miembros en caso de conflicto entre unidades políticas organizadas, porque rechaza la violencia y porque estima, además, que los diferendos se deben resolver por la vía legal o bien a través de la negociación. Pero tras este argumento formal queda la sospecha de que el liberalismo debido a su mixtura de individualismo y relativismo termina por considerar que no vale la pena sacrificarse por ningún ideal colectivo (nacional, comunitario o patriótico), porque no cree en la existencia de valores supraindividuales que tengan validez suprema o por lo menos vigencia incondicionada. Ningún valor es tan digno como para que merezca arriesgar la

\footnotetext{
${ }^{51}$ Schmitt, Carl: El Concepto de lo Político, 1991, p. 78.

${ }^{52}$ Cf. ibídem, p. 75.
} 
vida por él. Así, la paz en un mundo liberal, sería más el resultado de la falta de arrojo y valentía, que de un dispositivo óptimo de reglas para bloquear el uso de la violencia.

\section{Crítica al optimismo antropológico}

Toda teoría política parte de una concepción, ya sea de manera explícita o implícita, de la naturaleza humana y por consiguiente respecto de la bondad o maldad congénita del hombre ${ }^{53}$. El liberalismo parte del supuesto de que el hombre es bueno, por tanto, no requiere de un Estado fuerte para que limite la expresión de sus instintos, de su agresividad, de sus pasiones. Lo anterior no significa en modo alguno que el liberalismo niegue de manera radical al Estado. Para el liberalismo el Estado es un mal necesario. Entonces, para que no se exceda en sus atribuciones y evitar que se transforme en una amenaza para la sociedad, el liberalismo ha ideado tres instancias para controlar al Leviatán. En primer lugar, el Estado se autolimita mediante un sistema de contrapesos internos denominados división de poderes; en seguida, su proceder debe ajustarse siempre a la legalidad vigente; $y$, finalmente, sus autoridades son sometidas periódicamente a evaluación a través del mecanismo de las elecciones. Así, lo que el liberalismo deja en pie del Estado y de la política es únicamente el cometido de garantizar las condiciones de la libertad y de remover todos aquellos obstáculos que impidan su desarrollo.

En definitiva, en un mundo habitado por hombres buenos reinaría la paz, la seguridad y la armonía de todos con todos y el Estado sería innecesario. En un mundo así, "los curas y teólogos harían tan poca falta como los políticos y los estadistas" ${ }^{4}$, concluye Schmitt.

\section{Consideraciones finales}

Para Carl Schmitt el liberalismo elude y niega sistemáticamente la política ${ }^{55}$, pero ello no implica en modo alguno que sea antipolítico. Por el contrario, para Schmitt el liberalismo es una ideología intrínsecamente política, en cuanto, por una parte, astutamente encubre la política bajo el ropaje de lo jurídico y, por otra, transmuta lo político artificiosamente en compe-

${ }^{53}$ Cf. Schmitt, Carl: Teología Política, 1988, pp. 77-78. También véase Schmitt, Carl: Catolicismo y Forma Política, 2000, p. 9 y El Concepto de lo Político, 1991, p. 90.

54 Schmitt, Carl: El Concepto de lo Político, 1991, p. 93.

${ }^{55}$ Cf. ibídem, pp. 97 y 98. 
tencia económica o bien en una discusión ética que resulta ser inofensiva en un mundo caracterizado por el individualismo y el relativismo axiológico que él mismo ha contribuido a crear. Para Schmitt "la determinación de aquello que es y que no es político tiene un carácter político; asimismo la resolución sobre la mayor o menor politicidad de una materia es siempre [una cuestión] política, aun cuando se formule en un sentido negativo. El refugiarse en la apoliticidad puede ser la expresión más odiosa y peligrosa de la actividad política”56. Así, por ejemplo, el liberalismo aparentemente despolitiza y despersonaliza la política al reducirla al derecho. Mandan las normas y no las personas. Sin embargo, las resoluciones judiciales, aparentemente asépticas, son elaboradas en función de las normas que han sido previamente creadas, pero el contenido de éstas no es en modo alguno ajeno a móviles e intereses políticos concretos. En efecto, para Schmitt "la soberanía del derecho significa únicamente la soberanía de los hombres que imponen las normas jurídicas y se sirven de ellas" 57 . Por lo tanto, "el imperio del derecho no significa otra cosa que la legitimación de un determinado status quo en cuyo mantenimiento están lógicamente interesados todos aquellos cuyo poder político o ventaja económica poseen su estabilidad en el seno de ese derecho"58. En definitiva, para Schmitt, “detrás de cada ley terrenal hay inmediatamente hombres que se sirven de ella como un medio para su poder"59.

La crítica de Carl Schmitt al liberalismo es efectuada desde la óptica del realismo político. Quizás el mérito de Schmitt es haber combatido al liberalismo en el plano político con categorías políticas y usando una estrategia muy simple: haciendo comparecer a los ideales del liberalismo ante la realidad; cuando el liberalismo argumenta desde la idea, Schmitt replica con contrargumentos que extrae de la observación empírica. Schmitt en su manera de argumentar no solamente es un realista, sino que además tiene algo de sofista. En sus planteamientos, al lector le parece estar escuchando las palabras de los embajadores atenienses en la isla de Melos y también las murmuraciones de algunos sofistas, cuyos planteamientos conocemos a través de Platón. En mi opinión, el realismo político de Schmitt tiene cierto paralelismo con el realismo de Tucídides, quien nos enseñó que "los poderosos consideran honroso lo que les gusta y justo lo que les conviene" ${ }^{\prime 0} \mathrm{y}$ también con dos interlocutores de Sócrates: Calicles y Trasímaco. Este último sostenía que "en cada Estado la justicia no es más que la conveniencia

\footnotetext{
${ }^{56}$ Schmitt, Carl: Escritos de Política Mundial, 1995, p. 59.

${ }^{57}$ Schmitt, Carl: El Concepto de lo Político, 1991, p. 95.

58 Ibídem.

${ }^{59}$ Schmitt, Carl: Legalidad y Legitimidad, 1994, p. 119.
} 
del que tiene la autoridad en sus manos y, por consiguiente, del más fuerte. En todas partes, en efecto, la justicia y lo que es conveniente para el más fuerte son una misma cosa”61.

\section{BiBLIOGRAFÍA}

Carl Schmitt: El Concepto de lo Político. Madrid: Editorial Alianza, 1991.

Carl Schmitt: La Dictadura, desde los Comienzos del Pensamiento Moderno de la Soberanía hasta la Lucha Proletaria. Madrid: Editorial Alianza, 1999.

Carl Schmitt: Teología Política. Buenos Aires: Editorial Struhart \& Cía., 1998.

Carl Schmitt: Legalidad y Legitimidad. Buenos Aires: Editorial Struhart \& Cía., 1994.

Carl Schmitt: El Leviatán en la Teoría del Estado de Thomas Hobbes. Buenos Aires: Editorial Struhart \& Cía., 1998.

Carl Schmitt: Sobre el Parlamentarismo. Madrid: Editorial Técnos, 1990.

Carl Schmitt: Sobre los Tres Modos de Pensar la Ciencia Jurídica. Madrid: Editorial Técnos, 1996.

Carl Schmitt: Catolicismo y Forma Política. Madrid: Editorial Técnos, 2000.

Carl Schmitt: Escritos de Política Mundial. Buenos Aires: Editorial Heracles, 1995.

Carl Schmitt: "El Imperialismo Moderno en el Derecho Internacional Público". En Héctor Orestes Aguilar (comp.), Carl Schmitt, Teólogo de la Política. México: Fondo de Cultura Económica, 2001.

Maquiavello, Nicolás: El Príncipe. Madrid: Editorial Tecnos, 1993.

Fukuyama, Francis: ¿El Fin de la Historia? En Estudios Públicos, № 37, 1991.

Platón: La República. Traducción de Patricio Azcárate. Madrid: Ed. Espasa-Calpe, 2000. Tucídides: Historia de la Guerra del Peloponeso. Traducción de Juan José Torres. Madrid: Editorial Gredos, 2000.

${ }^{60}$ Tucídides de Atenas: Historia de la Guerra del Peloponeso, Libro V, capítulo ${ }^{61}$ Platón: Rep. 339 a-b. (Lib. I, cap. 12). 